\title{
Population Diversity within Isolates of Colletotrichum spp. Causing Glomerella Leaf Spot and Bitter Rot of Apples in Three Orchards in North Carolina
}

\author{
Eugenia González and Turner B. Sutton, Department of Plant Pathology, North Carolina State University, Raleigh \\ 27695
}

\begin{abstract}
González, E., and Sutton, T. B. 2004. Population diversity within isolates of Colletotrichum spp. causing Glomerella leaf spot and bitter rot of apples in three orchards in North Carolina. Plant Dis. 88:1335-1340.

The population diversity within isolates of Glomerella cingulata and Colletotrichum spp. associated with Glomerella leaf spot and bitter rot of apples was studied in an orchard of cv. Granny Smith located in Wilkes County, NC, and one orchard each of cultivars Granny Smith and Gala located in Lincoln County, NC. Morphological characters and vegetative compatibility groups (VCGs) were used to determine diversity within the species. The relative frequencies of the morphological types found within each species in each orchard were also determined. G. cingulata was the predominant species associated with bitter rot in the three orchards and Glomerella leaf spot in the Gala orchard. In the three orchards, different morphological types were observed within isolates of G. cingulata and Colletotrichum acutatum, but not within isolates of Colletotrichum gloeosporioides. Isolates of $C$. gloeosporioides were not found in the orchard of $\mathrm{cv}$. Granny Smith in Lincoln County. In the other two orchards, $C$. gloeosporioides represented the lowest proportion of the population. Three VCGs were found among isolates of $G$. cingulata (VCG-1, 2, and 6), two among isolates of C. gloeosporioides (VCG-9 and 10), and two among isolates of C. acutatum (VCG-15 and 16). VCGs 2, 6, 9, 10, 15, and 16 were found in the Granny Smith orchard in Wilkes County, VCGs 1, 2, and 6 in the Gala orchard in Lincoln County, and VCGs 2 and 6 in the Granny Smith orchard in Lincoln County. Differences in frequencies among the different morphological types found within the three orchards remained relatively similar throughout the season and from year to year, suggesting that the relative frequencies of G. cingulata, C. gloeosporioides, and C. acutatum remain stable in an orchard once the fungi are established.
\end{abstract}

Additional keywords: chromogenic type, perithecial type

Bitter rot is a common disease of apples in practically all countries were they are commercially grown. In moist and temperate growing regions, it can cause crop losses as high as 50\% (24). Three species, Glomerella cingulata (Stonem.) Spauld. \& Schrenk, Colletotrichum gloeosporioides (Penz.) Penz. \& Sacc., and C. acutatum J.H. Simmonds, are associated with the bitter rot disease of apples (24). Homothallic isolates of $C$. gloeosporioides from apple that produce fertile perithecia have been designated $G$. cingulata (22). Prior to 1965 , C. acutatum was considered to be one of the many morphological variants synonymous with $C$. gloeosporioides (5). However, cultural and morphological characteristics of $C$. acutatum, including slower growth rate and predominantly ellipsoidal, fusiform conidia produced in bright orange masses or borne directly on

Corresponding author: Turner B. Sutton

E-mail: turner_sutton@ncsu.edu

Accepted for publication 29 June 2004.

Publication no. D-2004-1015-02R

(C) 2004 The American Phytopathological Society the mycelium, differentiate it from $C$. gloeosporioides $(1,4,10,14-18,22,26)$. The presence of a pink to red pigment in the growing medium has frequently been observed for some isolates of $C$. acutatum, often characterized as chromogenic isolates $(10,14,18,22,28)$. In addition, several researchers have described distinct molecular and genetic differences between $C$. gloeosporioides and C. acutatum $(2,3,11$, 15-17,27,28).

Shi et al. (22) found that C. acutatum was the most abundant species associated with bitter rot in apple orchards in Arkansas, North Carolina, and Virginia. Almost $70 \%$ of the isolates recovered were identified as $C$. acutatum; the remaining were isolates of C. gloeosporioides, $40 \%$ of which produced the teleomorph, G. cingulata. In their study, isolates of Colletotrichum spp. were differentiated based on morphological characteristics, such as conidial morphology, production of perithecia in culture, and colony color. In another study, Lathan and Williams (19) found that $58 \%$ of the isolates recovered from fruit with bitter rot symptoms from an apple orchard located in Alabama were of the chromogenic type (C. acutatum), $32 \%$ were identified as perithecial types (homothallic isolates of C. gloeosporioides), and only $3 \%$ as nonchromogenic isolates. Both of these studies were based on relatively small samples collected at one time during the season $(19,22)$.

In addition to causing bitter rot, a strain of $G$. cingulata also has been reported to cause a leaf spot on the cultivars Gala and Golden Delicious in Paraná State in Brazil (20). The disease, named Glomerella leaf spot (GLS), causes $75 \%$ or more defoliation by harvest under favorable conditions, which weakens apple trees and reduces yield $(6,20,25)$. GLS requires a more intensive management program than bitter rot (Rosa María Sanhueza, personal communication). In the United States, Glomerella leaf spot was first reported in 1998, when it was observed causing a severe leaf spot in two orchards of cv. Gala in eastern Tennessee (13) and has subsequently been found in Georgia and North Carolina (12). Currently, a management program for GLS has not been developed for use in the United States.

A vegetative compatibility analysis of isolates of Colletotrichum spp. associated with bitter rot and GLS of apples found a high diversity within isolates of $C$. gloeosporioides, C. acutatum, and $G$. cingulata obtained from apples collected in different locations in the United States (12). This analysis distinguished between isolates of G. cingulata that cause only bitter rot and those that cause both bitter rot and GLS. Although some of the vegetative compatibility groups (VCGs) found among these three species were present in the majority of the locations from which the isolates were collected, some VCGs were found only in certain locations, suggesting a cultivar and location specificity for these VCGs. Additionally, the VCG associated with isolates capable of causing GLS was only found in apple orchards of cv. Gala. These results suggest that the emergence of GLS in the United States was influenced by cultivar. Environmental factors and management practices can also influence the diversity of fungi associated with bitter rot (22). Therefore, knowledge of differences in the morphological and genetic variation of Colletotrichum spp. found within orchards with a history of bitter rot only and those with GLS and bitter rot could provide valuable information for developing management and control strategies for these two diseases. 
The objective of this study was to determine the population diversity within isolates of $C$. acutatum, $C$. gloeosporioides, and $G$. cingulata and their relative frequencies in two apple orchards of cv. Granny Smith located in North Carolina in areas with different environmental and management conditions and an orchard of cv. Gala, also located in North Carolina, where GLS was first observed in this state.

\section{MATERIALS AND METHODS}

Origin of the isolates and sampling protocol. An orchard of cv. Granny Smith located in Wilkes County, NC, and one orchard each of cultivars Granny Smith and Gala located in Lincoln County, NC, were surveyed to study the diversity of the population of $G$. cingulata, C. gloeosporioides, and $C$. acutatum associated with Glomerella leaf spot and bitter rot of apples. Fruit samples from the two Granny Smith orchards located in Wilkes and Lincoln counties were collected every 2 weeks from June through September, four times in 2001 and three times in 2002. Sampling was initiated when symptoms first appeared and continued every 2 weeks, except the Wilkes County orchard, which was sampled only once in 2003, on 15 September. Samples in the Granny Smith orchard in Wilkes County were taken on 27 July, 10 and 29 August, and 12 September in 2001. In the two Granny Smith orchards, samples were taken on 12 and 27 August and 11 September in 2002, and in the Gala orchard on 1, 15, and 29 July and 15 August in 2003. In the Wilkes County orchard, samples of eight fruit showing typical symptoms of bitter rot were taken from each of 20 arbitrarily selected trees

Table 1. Isolates of Colletotrichum acutatum, C. gloeosporioides, and Glomerella cingulata obtained from leaf and fruit samples collected from two different apple orchards of cv. Granny Smith and an orchard of cv. Gala located in North Carolina

\begin{tabular}{|c|c|c|c|c|c|}
\hline \multirow[b]{2}{*}{ Species $^{y}$} & \multirow{2}{*}{$\begin{array}{c}\text { Origin } \\
\text { (county) }\end{array}$} & \multicolumn{2}{|c|}{ Source } & \multirow{2}{*}{$\begin{array}{l}\text { Isolates } \\
\text { recovered }^{\mathrm{z}}\end{array}$} & \multirow{2}{*}{$\begin{array}{c}\text { Year } \\
\text { collected }\end{array}$} \\
\hline & & Host tissue & Cultivar & & \\
\hline C. acutatum & Wilkes & Fruit & Granny Smith & 116 & 2001 \\
\hline C. acutatum & Wilkes & Fruit & Granny Smith & 66 & 2002 \\
\hline C. acutatum & Wilkes & Fruit & Granny Smith & 11 & 2003 \\
\hline C. acutatum & Lincoln & Fruit & Granny Smith & 5 & 2002 \\
\hline C. acutatum & Lincoln & Fruit & Gala & 150 & 2003 \\
\hline C. acutatum & Lincoln & Leaf & Gala & 160 & 2003 \\
\hline C. gloeosporioides & Wilkes & Fruit & Granny Smith & 13 & 2001 \\
\hline C. gloeosporioides & Wilkes & Fruit & Granny Smith & 11 & 2002 \\
\hline C. gloeosporioides & Wilkes & Fruit & Granny Smith & 2 & 2003 \\
\hline C. gloeosporioides & Lincoln & Fruit & Gala & 2 & 2003 \\
\hline C. gloeosporioides & Lincoln & Leaf & Gala & 2 & 2003 \\
\hline G. cingulata & Wilkes & Fruit & Granny Smith & 343 & 2001 \\
\hline G. cingulata & Wilkes & Fruit & Granny Smith & 296 & 2002 \\
\hline G. cingulata & Wilkes & Fruit & Granny Smith & 117 & 2003 \\
\hline G. cingulata & Lincoln & Fruit & Granny Smith & 250 & 2002 \\
\hline G. cingulata & Lincoln & Fruit & Gala & 247 & 2003 \\
\hline G. cingulata & Lincoln & Leaf & Gala & 609 & 2003 \\
\hline
\end{tabular}

${ }^{y}$ Species designation was assigned after morphological characterization.

${ }^{\mathrm{z}}$ Total number of isolates recovered throughout the season in each of the orchards sampled. within every two rows in the orchard, for a total of 160 fruit per sample date. In order to eliminate biases in the selection of infected fruit, each tree was divided into four sampling quadrats, and subsamples containing two fruit were collected from each quadrat. A predetermined height, depth, and angle were used to establish the position in the tree canopy to collect the fruit. Each of the four quadrats within the 20 trees was tagged with numbers from 1 to 4 , and different heights, depths, and angles were randomly selected for each quadrat on each sample date. Sample measures for quadrats with the same numbers were equal for all trees and were reselected every sample date. In the orchards located in Lincoln County, eight fruit samples were collected from an arbitrarily selected tree within each of 18 rows in the orchard, for a total of 144 fruit per sample date. In these orchards, fruit samples were collected arbitrarily from any part of the tree canopy to complete the eight-fruit sample. Leaves with symptoms of GLS were also collected from the orchard of cv. Gala from the same 18 trees sampled for bitter rot on fruit. Twenty or more leaves were collected arbitrarily from each tree.

Isolations. Fruit and leaf samples obtained in the orchard were kept at $4{ }^{\circ} \mathrm{C}$ until they were processed, 1 to 7 days later. Fruit and leaves selected for the isolations were disinfested with $70 \%$ ethanol and $0.525 \% \mathrm{NaOCl}$ for $30 \mathrm{~s}$, respectively, and allowed to dry in a laminar hood. Fungi were recovered from small pieces cut from a lesion arbitrarily selected on each fruit collected. Fungi were also recovered from at least one small piece of leaf tissue selected from each of the leaves in the sample collected from each tree, to complete a total of 32 leaf pieces per tree. If the sample had less than 32 leaves, two pieces of leaf tissue were selected from some of the leaves. Fruit isolates were placed in petri

Table 2. Description of morphological types of isolates of Colletotrichum acutatum, C. gloeosporioides, and Glomerella cingulata based on colony color, conidial shape, ability to produce perithecia in culture, and distribution of acervuli and perithecia in culture ${ }^{\mathrm{x}}$

\begin{tabular}{|c|c|c|c|c|c|c|}
\hline \multirow[b]{2}{*}{ Species } & \multirow{2}{*}{$\begin{array}{l}\text { Morphological } \\
\text { type }\end{array}$} & \multicolumn{2}{|r|}{ Perithecia } & \multirow{2}{*}{$\begin{array}{l}\text { Acervuli and } \\
\text { perithecia }^{y}\end{array}$} & \multirow[b]{2}{*}{ Colony } & \multirow[b]{2}{*}{ Conidial shape } \\
\hline & & Fertility & Distribution & & & \\
\hline G. cingulata & SP1 & Self-fertile & $\begin{array}{l}\text { Single or small groups } \\
\text { over entire colony }\end{array}$ & $a / p$ & $\begin{array}{c}\text { Dark gray, sparse, and } \\
\text { appressed mycelium }\end{array}$ & $\begin{array}{l}\text { Cylindrical with } \\
\text { rounded ends }\end{array}$ \\
\hline G. cingulata & $\mathrm{SP} 2$ & Self-fertile & Scattered small groups & $a / p$ & $\begin{array}{l}\text { Gray and appressed } \\
\text { mycelium }\end{array}$ & $\begin{array}{l}\text { Cylindrical with } \\
\text { rounded ends }\end{array}$ \\
\hline \multirow[t]{2}{*}{ G. cingulata } & $\mathrm{CP}$ & Self-fertile & Scattered clumps & $a / p$ & $\begin{array}{l}\text { Gray/white and abundant } \\
\text { mycelium }\end{array}$ & $\begin{array}{l}\text { Cylindrical with } \\
\text { rounded ends }\end{array}$ \\
\hline & & Acervuli color & Conidia distribution & & & \\
\hline C. gloeosporioides & SS1 & Light & $\begin{array}{c}\text { Small orange masses } \\
\text { over entire colony }\end{array}$ & $a$ & $\begin{array}{l}\text { Light gray and appressed } \\
\text { mycelium }\end{array}$ & $\begin{array}{l}\text { Cylindrical with } \\
\text { rounded ends }\end{array}$ \\
\hline C. gloeosporioides & SS3 & Dark & $\begin{array}{l}\text { Large orange scattered } \\
\text { masses }\end{array}$ & $a$ & $\begin{array}{l}\text { Light gray and abundant } \\
\text { mycelium }\end{array}$ & $\begin{array}{l}\text { Cylindrical with } \\
\text { rounded ends }\end{array}$ \\
\hline C. acutatum & SSC & $\mathrm{n} / \mathrm{a}^{\mathrm{z}}$ & Mostly within mycelium & $a$ & Red pigment in culture & $\begin{array}{l}\text { Fusiform with } \\
\text { pointed ends }\end{array}$ \\
\hline C. acutatum & SSNC & $\mathrm{n} / \mathrm{a}$ & Mostly within mycelium & $a$ & Gray-olive, no pigment & $\begin{array}{l}\text { Fusiform with } \\
\text { pointed ends }\end{array}$ \\
\hline
\end{tabular}

${ }^{\mathrm{x}}$ Eight to 15 -day-old isolates grown on potato dextrose agar medium were characterized after incubation at $25^{\circ} \mathrm{C}$ with constant light.

${ }^{\text {y }} a$ indicates presence of acervuli in culture; $p$ indicates presence of perithecia in culture.

${ }^{\mathrm{z}} \mathrm{n} / \mathrm{a}=$ isolates did not produce acervuli in culture. 
dishes containing potato dextrose agar (PDA) and leaf isolates in petri dishes containing PDA + streptomycin (200 $\mu \mathrm{g} / \mathrm{ml})$. Isolates were incubated in a growth chamber at $25^{\circ} \mathrm{C}$ and constant light for 24 $\mathrm{h}$ for 7 to 20 days. Although the isolation protocol could have resulted in 160 fruit isolates from the Wilkes County orchard, 144 fruit isolates from the Lincoln County orchards, and 576 leaf isolates from the orchard of cv. Gala for each sample date, some trees did not have enough symptomatic fruit to obtain the eight-fruit sample, and some cultures were contaminated with bacteria or fungi not associated with Glomerella leaf spot or bitter rot. Consequently, in the Wilkes County orchard, totals of $101,88,140$, and 143 fruit isolates were recovered in 2001 on the four sample dates, totals of 129,130 , and 114 on the three sample dates in 2002, and a total of 130 in 2003. In the Lincoln County orchard of cv. Granny Smith, 26, 123, and 106 fruit isolates were recovered on the three sample dates in 2002. In the orchard of cv. Gala, 100, 93, 103, and 103 fruit isolates, and 230, 194, 202, and 145 leaf isolates were obtained on the four sample dates in 2003 (Table 1).

Monosporic isolates were obtained from each of the isolates. Perithecia or conidia from isolates growing on PDA or PDA amended with streptomycin were placed in a drop of deionized water on a microscope slide. Perithecia were covered with a coverslip and were crushed to release the ascospores by gently pressing down the coverslip. Then the crushed perithecia and ascospores were washed with a few drops of sterile deionized water into a petri dish containing water agar (WA). Conidia were directly washed from slides into the WA dishes. WA dishes containing crushed perithecia or conidia were incubated at $25^{\circ} \mathrm{C}$ and constant light for 10 to $15 \mathrm{~h}$ until the spores germinated. Single germinated spores were transferred to another petri dish containing WA. Fungal colonies emerging from isolates growing on WA were hyphal-tip-transferred onto dishes of PDA. Monosporic isolates were stored desiccated on filter paper at $5^{\circ} \mathrm{C}$ as described previously (8).

Morphological characterization and VCG analysis. All fruit and leaf isolates recovered in this experiment were differentiated based on colony color, conidial shape, the ability to produce perithecia in culture, and distribution of acervuli and perithecia in culture (Table 2). To complement the morphological characterization, a subset of 275 isolates, including isolates from each of the different morphological types observed in the original samples obtained from the three orchards, was further characterized by VCG. These isolates were part of a larger group of isolates tested for vegetative compatibility and characterized using mtDNA restriction fragment length polymorphism (RFLP) haplotypes and the sequence of a 200-bp intron of the glyceraldehyde 3-phosphate dehydrogenase (GDPH) nuclear gene in previous studies (12). Nit mutants were recovered by transferring fast-growing sectors of monosporic isolates growing on minimal agar medium containing potassium chlorate to a minimal agar medium without chlorate $(7,21)$. Sixteen pairs of complementing nit mutant testers were identified among the monosporic isolates. Mutant testers were arbitrarily named from VCG-1 to VCG-16. Vegetative compatibility of all nit mutants generated from a collection of 486 monosporic isolates was determined by pairing them on minimal medium with at least one of the testers.

\section{RESULTS}

Morphological characterization. Seven morphological types were observed among the 2,390 isolates of $G$. cingulata, $C$. gloeosporioides, and C. acutatum examined (Table 2). Isolates of G. cingulata and C. gloeosporioides produced cylindrical conidia with rounded ends and were differentiated by the ability of the self-fertile isolates to produce perithecia in culture. Isolates of $G$. cingulata were separated into three morphological types (SP1, SP2, and $\mathrm{CP}$ ) mainly distinguished by the dis-
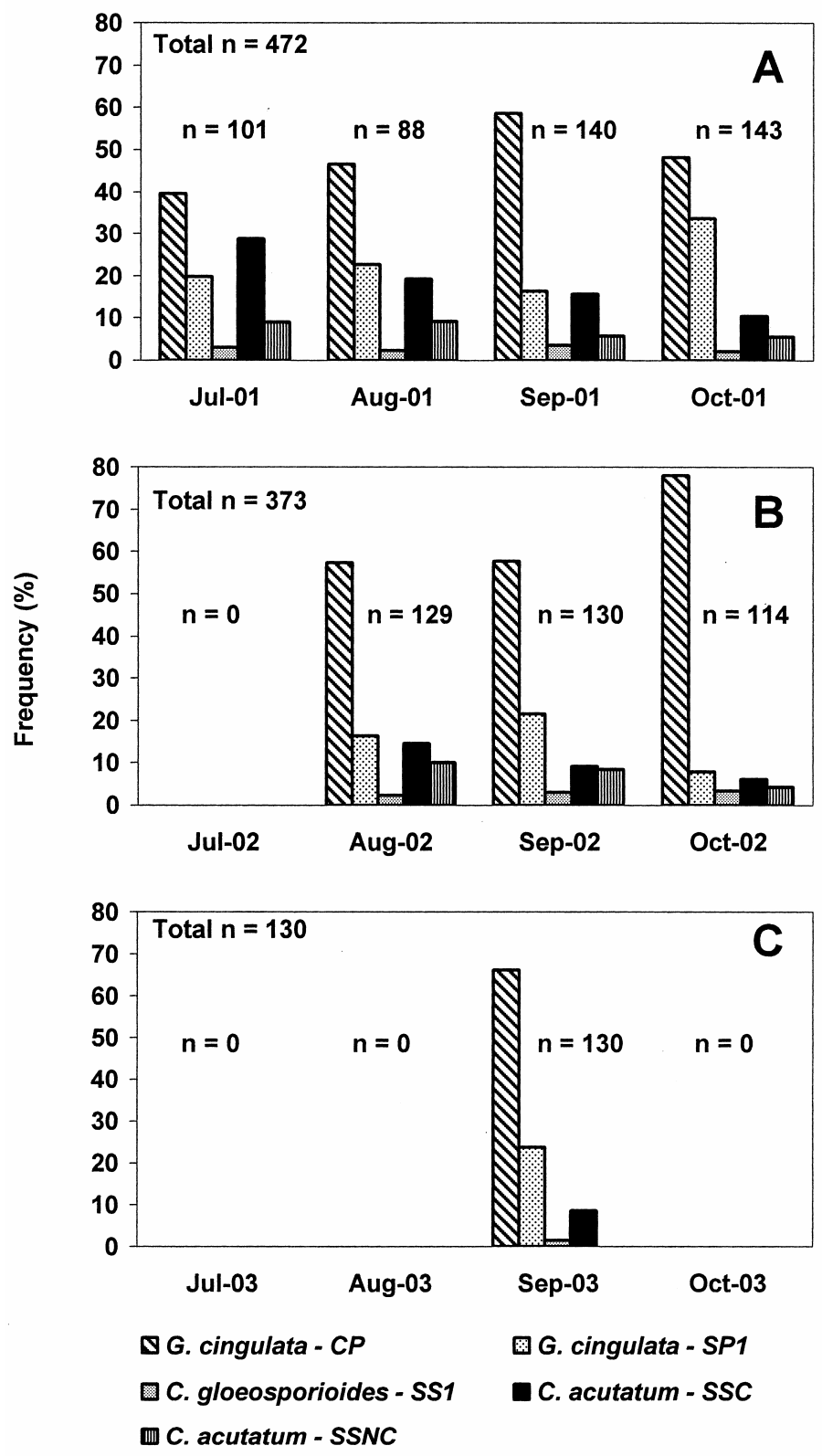

Fig. 1. Frequencies of morphological types of fruit isolates of Colletotrichum acutatum (SSC and SSNC), C. gloeosporioides (SS1), and Glomerella cingulata (CP and SP1) recovered from an orchard of cv. Granny Smith located in Wilkes County, NC, during A, 2001, B, 2002, and C, 2003. Fruit samples were collected monthly from 20 arbitrarily selected trees within the orchard. Morphological types are described in Table 2. Frequency represents percentage of isolates of a certain morphological type with respect to the total number of isolates recovered in each sampling date. Total $\mathrm{n}=$ total number of fruit collected; $\mathrm{n}=$ number of fruit collected per sample date. 


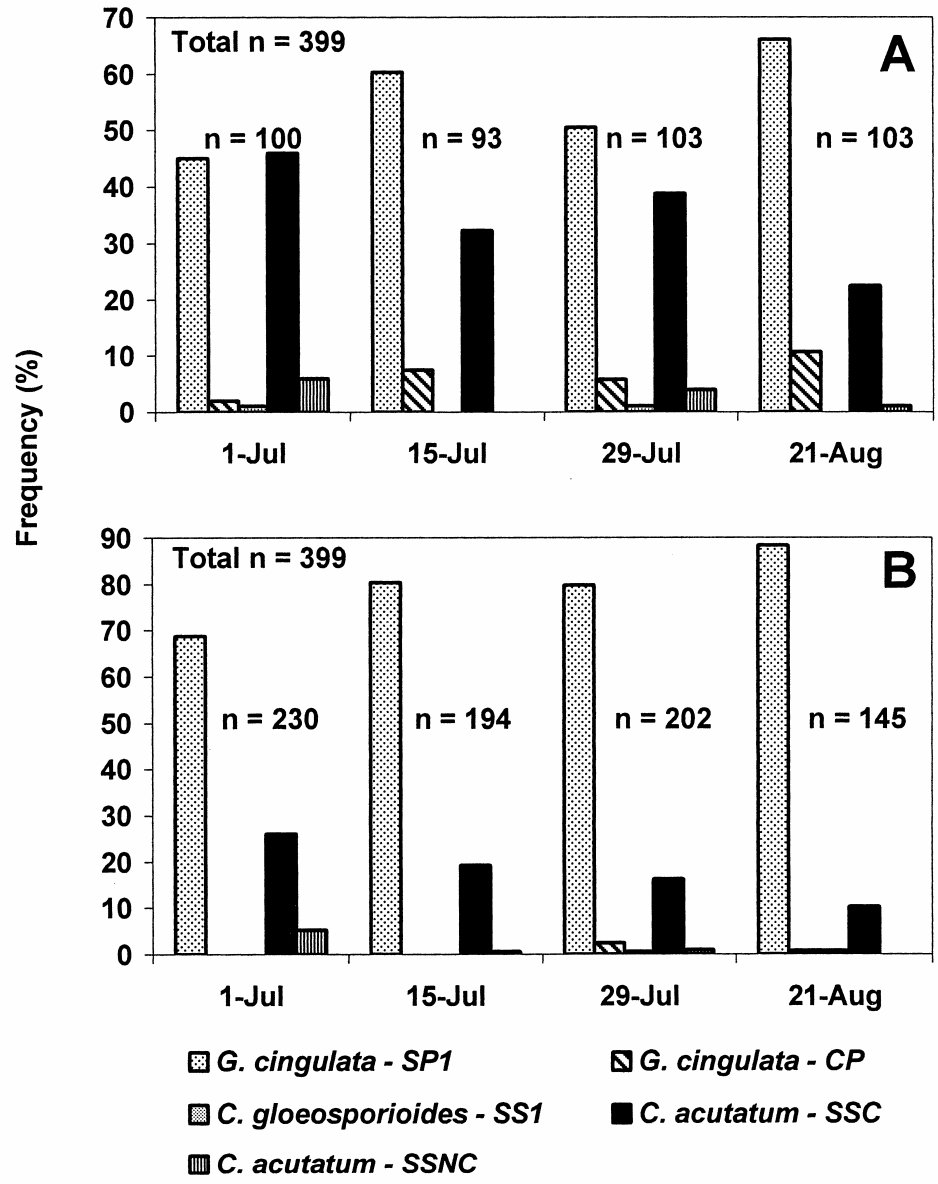

Fig. 2. Frequencies of morphological types of fruit (A) and leaf (B) isolates of Colletotrichum acutatum (SSC and SSNC), C. gloeosporioides (SS1), and Glomerella cingulata (SP1 and CP) recovered from an orchard of cv. Gala located in Lincoln County, NC, during 2003. Fruit samples were collected every 2 weeks from 18 arbitrarily selected trees within the orchard. Morphological types are described in Table 2. Frequency represents percentage of isolates of a certain morphological type with respect to the total number of isolates recovered in each sampling date. Total $\mathrm{n}=$ total number of fruit collected; $\mathrm{n}=$ number of fruit collected per sample date.

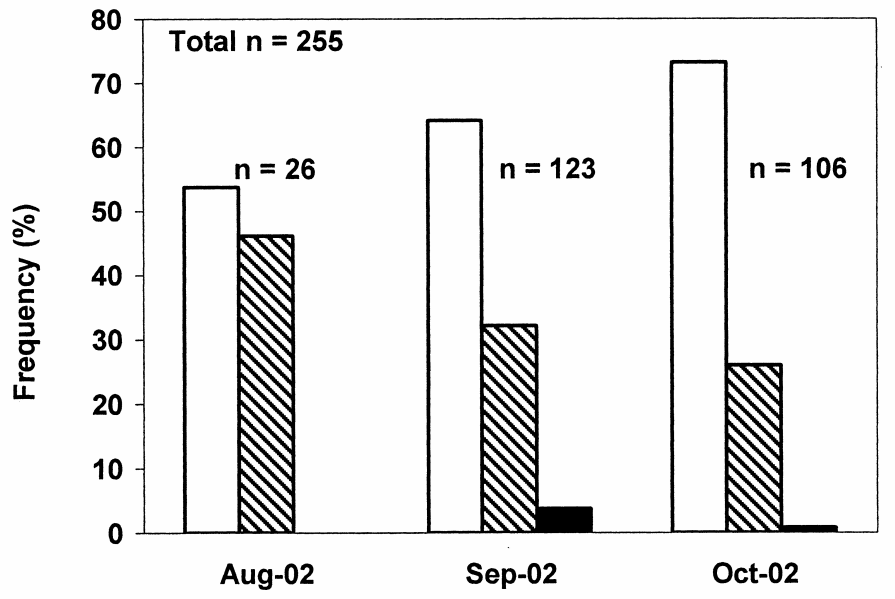

$\square G$. cingulata - SP2 $\triangle G$. cingulata - CP $\square$ C. acutatum - SSC

Fig. 3. Frequencies of morphological types of fruit isolates of Colletotrichum acutatum (SSC) and Glomerella cingulata (CP and SP2) recovered from an orchard of cv. Granny Smith located in Lincoln County, NC, during 2002. Fruit samples were collected monthly from 18 arbitrarily selected trees within the orchard. Morphological types are described in Table 2. Frequency represents percentage of isolates of a certain morphological type with respect to the total number of isolates recovered in each sampling date. Total $\mathrm{n}=$ total number of fruit collected; $\mathrm{n}=$ number of fruit collected per sample date. tribution of perithecia in culture. Isolates of $C$. gloeosporioides were separated into two morphological types (SS1 and SS3) mainly differentiated by the distribution of conidial masses in culture and colony color. Two morphological types were found among isolates of $C$. acutatum (SSC and SSNC). These morphological types were distinguished by the presence of red pigment in culture and colony color. All morphological types of $C$. acutatum produced fusiform conidia with pointed ends and none formed perithecia in culture. Conidia were produced mostly within the mycelium and some in orange masses scattered within the colonies. Detailed characteristics of the morphological types found within $G$. cingulata, $C$. gloeosporioides, and $C$. acutatum are presented in Table 2.

Morphological types and their frequency. Isolates of $G$. cingulata, $C$. gloeosporioides, and $C$. acutatum were found each year in the orchard of cv. Granny Smith located in Wilkes County (Fig. 1) and in the orchard of cv. Gala in Lincoln County (Fig. 2). However, only isolates of $G$. cingulata and C. acutatum were found in the orchard of cv. Granny Smith located in Lincoln County (Fig. 3). Isolates of $G$. cingulata were more abundant than isolates of $C$. acutatum in all the orchards. In the Wilkes County orchard, isolates of $G$. cingulata and $C$. acutatum obtained from fruit comprised 60 to $90 \%$ and 11 to $29 \%$ of the population, respectively, and 96 to $100 \%$ and 1 to $4 \%$, in the Lincoln County orchard of cv. Granny Smith during the sampling period. In the orchard of cv. Gala, fruit isolates of $G$. cingulata and $C$. acutatum comprised 47 to $77 \%$ and 23 to $52 \%$ of the population, respectively. In that same orchard, isolates of $G$. cingulata and C. acutatum obtained from leaves comprised 69 to $89 \%$ and 10 to $31 \%$ of the population, respectively. C. gloeosporioides was the least common taxa found on fruit in the Wilkes County orchard, representing only 2 to $4 \%$ of the population (Fig 1). It was also the least common taxa recovered from leaves or fruit in the orchard of cv. Gala, representing only 0 to $1 \%$ of the population (Fig. 2).

Three morphological types were found within isolates of G. cingulata (SP1, SP2, and $\mathrm{CP}$ ) in the three orchards (Figs. 1 to 3). CP was found in all three orchards, SP1 was found in the Wilkes County orchard and the orchard of cv. Gala, and SP2 was found only in the orchard of cv. Granny Smith located in Lincoln County. CP isolates were the most abundant isolates obtained from the Wilkes County orchard, with frequencies between 40 and $78 \%$. SP1 isolates comprised 8 to $38 \%$ of the population in the Wilkes County orchard. In the Lincoln County orchard of cv. Granny Smith, CP isolates represented 26 to $46 \%$ of the population, but frequencies of the SP2 isolates were higher and ranged 
from 54 to $73 \%$. In the orchard of cv. Gala, $\mathrm{CP}$ fruit isolates represented 2 to $11 \%$ of the population and $\mathrm{CP}$ leaf isolates were found only on the last two sample dates and represented only 1 to $3 \%$ of the population. SP1 isolates had the higher frequencies in this orchard and ranged from 45 to $66 \%$ for fruit isolates and from 60 to $88 \%$ for leaf isolates. All isolates of $C$. gloeosporioides were characterized as SS1-type cultures and were isolated from fruit in the Granny Smith orchard in Wilkes County and in the orchard of cv. Gala in Lincoln County. Isolates of $C$. acutatum were separated in two morphological types (SSC and SSNC). SSNC fruit isolates were found in the Wilkes County orchard and the orchard of cv. Gala and represented 4 to $10 \%$ and 1 to $6 \%$ of the population, respectively. In the orchard of cv. Gala, SSNC fruit isolates represented 0.5 to $5 \%$ of the population. SSC fruit isolates were more abundant than SSNC isolates, with frequencies between 6 and $29 \%$ in the Wilkes County orchard, 1 and $4 \%$ in the Lincoln County orchard of cv. Granny Smith, and 22 and $46 \%$ in the orchard of cv. Gala. SSC leaf isolates were also more abundant than SSNC isolates in the orchard of cv. Gala, with frequencies of 10 to $26 \%$.

Differences in frequencies among the different morphological types found within the three orchards remained relatively similar throughout the season, both in 2001 and 2002. However, in October of 2001, the number of SP1 isolates in the Wilkes County orchard was proportionally higher than at other sample dates throughout the season. In October of 2002, CP isolates were more abundant than at any other time of the season; the other morphological types only represented 4 to $8 \%$ of the population. In addition, isolates of $G$. cingulata were more abundant in 2002 and 2003 than in 2001 in the Wilkes County orchard.

VCGs associated with morphological types. Three different VCGs were found among leaf and fruit isolates of G. cingulata in the orchard of cv. Gala (VCG-1, VCG-2, and VCG-6) (Table 3). Leaf and fruit isolates of SP1-type belonged in VCG-1 and VCG-2, and fruit isolates in VCG-6 were characterized as CP-type cultures. VCG-2 and VCG-6 were also found in the orchard of cv. Granny Smith in Lincoln County. These isolates were characterized as SP2-type and CP-type, respectively. The orchard of cv. Granny Smith located in Wilkes County had the greatest VCG diversity. Six different VCGs were found in this orchard: VCG-2, 6, 9, 10,15 , and 16. VCG-2 and VCG-6 were also characterized as SP2-type and CPtype, respectively. VCG-9 and VCG-10 included isolates of $C$. gloeosporioides with an SS1 morphological type, and VCG-15 and VCG-16 included isolates of C. acutatum characterized as SSC and SSNC, respectively.

\section{DISCUSSION}

Three species were associated with GLS and bitter rot in the apple orchards surveyed, G. cingulata, C. gloeosporioides, and $C$. acutatum. The three species showed high morphological and genetic diversity. Additionally, some of the morphological types and VCGs associated with these species were not found in all orchards surveyed. Isolates of $G$. cingulata that belonged in VCG-1 were recovered only from leaves or fruit obtained from the Gala orchard where GLS had been observed.

The diversity of bitter rot fungi was greater in the Granny Smith orchard in Wilkes County and the Gala orchard in Lincoln County than in the Granny Smith orchard in Lincoln County. G. cingulata was the predominant species in all three orchards. Two morphological types of $G$. cingulata, representing two different VCGs, were observed in the Granny Smith orchards. CP-type isolates of G. cingulata predominated over SP1 in the Granny Smith orchard in Wilkes County and SP2 isolates in the Granny Smith orchard in
Lincoln County. However, SP1 was the predominant type in the Gala orchard. The morphological characteristics of CP-type isolates coincide with descriptions of isolates of $G$. cingulata commonly associated with bitter rot only $(22,23)$. C. acutatum was also represented by two morphological types that also belonged to two different VCGs. Chromogenic (SSC) isolates of C. acutatum predominated over nonchromogenic (SSNC) isolates. However, only chromogenic isolates were present in the Lincoln County orchard. C. gloeosporioides was the least abundant species in the population in the Wilkes County orchard and the Gala orchard in Lincoln County and was not observed in the Granny Smith orchard in Lincoln County. In a previous study of 11 apple orchards, C. acutatum was the predominant bitter rot fungus present in most of the orchards sampled (22), and the chromogenic isolates predominated over nonchromogenic isolates (22). G. cingulata and C. gloeosporioides were predominant species only in one and two orchards, respectively, of cv. Delicious.

Only SP1 isolates of G. cingulata recovered from fruit or leaves collected from the orchard of cv. Gala that belonged to VCG1 are pathogenic on leaves (12). Although isolates of $C$. acutatum were recovered from leaves, they were not pathogenic to leaves and were likely growing saprophytically in necrotic tissue. The origin of the isolates belonging to VCG-1 is unclear. G. cingulata, C. gloeosporioides, and $C$. acutatum have a diverse host range, affecting many plant species (9), and it is likely that these species play a role in establishing the initial population in an orchard. However, other factors such as environmental conditions, cultivar, management practices, and pesticide use (22) may ultimately determine the diversity of the population.

While environmental conditions influence the incidence and severity of bitter rot from year to year and location to location,

Table 3. Vegetative compatibility groups (VCGs) associated with the morphological types found among isolates of Colletotrichum acutatum, C. gloeosporioides, and Glomerella cingulata

\begin{tabular}{|c|c|c|c|c|c|c|}
\hline \multirow{2}{*}{$\begin{array}{l}\text { Morphological } \\
\text { type }^{x}\end{array}$} & \multirow[b]{2}{*}{$\mathrm{VCG}^{\mathrm{y}}$} & \multirow[b]{2}{*}{ Species } & \multirow[b]{2}{*}{ Isolates } & \multicolumn{2}{|c|}{ Source } & \multirow{2}{*}{$\begin{array}{l}\text { Origin } \\
\text { (county) }\end{array}$} \\
\hline & & & & Cultivar & Host tissue & \\
\hline SP1 & 1 & G. cingulata & 61 & Gala & Leaf & Lincoln \\
\hline SP1 & 1 & G. cingulata & 1 & Gala & Fruit & Lincoln \\
\hline SP1 & 2 & G. cingulata & 45 & Gala and Granny Smith & Fruit & Lincoln and Wilkes \\
\hline SP2 & 2 & G. cingulata & 30 & Granny Smith & Fruit & Lincoln \\
\hline $\mathrm{CP}$ & 6 & G. cingulata & 69 & Gala and Granny Smith & Fruit & Lincoln and Wilkes \\
\hline SS1 & 9 & C. gloeosporioides & 18 & Granny Smith & Fruit & Wilkes \\
\hline SS1 & 10 & C. gloeosporioides & 2 & Granny Smith & Fruit & Wilkes \\
\hline SS3 & $\mathrm{n} / \mathrm{a}^{\mathrm{z}}$ & C. gloeosporioides & 1 & Granny Smith & Fruit & Wilkes \\
\hline SSC & 15 & C. acutatum & 3 & Granny Smith & Fruit & Wilkes \\
\hline $\mathrm{SSC}$ & $\mathrm{n} / \mathrm{a}$ & C. acutatum & 21 & Gala and Granny Smith & Fruit & Lincoln and Wilkes \\
\hline SSNC & 16 & C. acutatum & 3 & Granny Smith & Fruit & Wilkes \\
\hline SSNC & $\mathrm{n} / \mathrm{a}$ & C. acutatum & 21 & Granny Smith & Fruit & Wilkes \\
\hline
\end{tabular}

${ }^{\mathrm{x}}$ Morphological types based on colony color, conidial shape, ability to produce perithecia in culture, and distribution of acervuli and perithecia in culture.

y According to VCG analysis conducted in a previous study (12).

${ }^{\mathrm{z}} \mathrm{n} / \mathrm{a}=$ isolates with this morphological type, origin, and source were not compatible with any of the VCGs. 
they do not appear to have great influence on the population diversity once it is initially established. The Wilkes County orchard has a history of high bitter rot incidence and typically is wetter than the Lincoln County orchards. It is possible that the fungicides used could affect the population diversity. In laboratory experiments, C. acutatum showed lower sensitivity to benomyl than $C$. gloeosporioides (12), but there is no evidence that fungicides have any differential activity on the species in the orchard. Our data indicate that cultivar exhibits a strong selective force, at least for the cultivar Gala. In the Gala orchard, the SP1 morphological type predominated, and it was the only orchard where VCG-1 was found. Since VCG-1 isolates were predominately associated with leaves, techniques that minimize inoculum density such as leaf shredding in the winter would be an important component of a program for managing GLS.

Once the fungi are established in an orchard, their relative frequencies appear to remain stable from year to year as well as throughout the growing season. In the Wilkes County orchard, the relative frequencies of the three taxa were similar throughout the three seasons, despite the fact that 2001 and 2003 were wet growing seasons and 2002 was very dry. Similarly, the relative frequencies of these fungi did not vary greatly among sample dates in any of the orchards. Additional studies are needed over more seasons and in more orchards to confirm our hypothesis that the relative frequencies of $G$. cingulata, $C$. gloeosporioides, and $C$. acutatum remain stable in an orchard once the fungi are established.

\section{ACKNOWLEDGMENTS}

We thank Mr. Jeff Crotts, owner of the orchards in Lincoln County, and Mr. Eddie Miller, owner of the orchard in Wilkes County, for allowing us to conduct our experiments in their orchards.

\section{LITERATURE CITED}

1. Adaskaveg, J. E., and Hartin, R. J. 1997. Characterization of Colletotrichum acutatum isolates causing anthracnose of almond and peach in California. Phytopathology 87:979-987.

2. Afanador-Kafuri, L., Minz, D., Maymon, M., and Freeman, S. 2003. Characterization of Colletotrichum isolates from tamarillo, passiflora, and mango in Colombia and identification of a unique species from the genus. Phytopathology 93:579-587.

3. Bernstein, B., Zehr, E. I., Dean, R. A., and Shabi, E. 1995. Characteristics of Colletotrichum from peach, apple, pecan, and other hosts. Plant Dis. 79:478-482.

4. Buddie, A. G., Martínez-Culebras, P., Bridge, P. D., García, M. D., Querol, A., Cannon, P. F., and Monte, E. 1999. Molecular characterization of Colletotrichum strains derived from strawberry. Mycol. Res. 103:385-394.

5. Cannon, P. F., Bridge, P. D., and Monte, E. 2000. Linking the past, present, and future of Colletotrichum systematics. Pages 1-20 in: Colletotrichum: Host Specificity, $\mathrm{Pa}-$ thology, and Host-Pathogen Interaction. D. Prusky, S. Freeman, and M. Dickman, eds. American Phytopathological Society, St. Paul, MN.

6. Cerezine, P. C., Leite, R. P., and Tsuneta, M. 1992. Efeito de tratamentos químicos no controle da mancha foliar de Glomerella en macieira, no estado de Paraná. Fitopatol. Bras. 17:258-267.

7. Correll, J. C., Klittich, J. R., and Leslie, J. F. 1987. Nitrate nonutilizing mutants of Fusarium oxysporum and their use in vegetative compatibility tests. Phytopathology 77:16401646.

8. Correll, J. C., Puhalla, J. E., and Schneider, R. W. 1986. Identification of Fusarium oxysporum $\mathrm{f}$. sp. apii on the basis of colony size, virulence, and vegetative compatibility. Phytopathology 73:396-400.

9. Farr, D. F., Bills, G. F., Chamuris, G. P., and Rossman, A. 1989. Fungi on Plants and Plant Product in the United States. American Phytopathological Society, St. Paul, MN.

10. Förster, H., and Adaskaveg, J. E. 1999. Identification of subpopulations of Colletotrichum acutatum and epidemiology of almond anthracnose in California. Phytopathology 89:1056-1065

11. Freeman, S., and Katan, T. 1997. Identification of Colletotrichum species responsible for anthracnose and root necrosis of strawberry in Israel. Phytopathology 87:516-521.

12. González, E. 2003. Characterization of isolates of Glomerella cingulata causal agent of Glomerella leaf spot and bitter rot of apples based on morphology and genetic, molecular, and pathogenicity tests. Ph.D. diss. North Carolina State University, Raleigh.

13. González, E., and Sutton, T. B. 1999. First report of Glomerella leaf spot (Glomerella cingulata) of apple in the United States. Plant Dis. 83:1074

14. Guerber, J. C., and Correll, J. C. 2001. Characterization of Glomerella acutata, the teleo- morph of Colletotrichum acutatum. Mycologia 93:216-229.

15. Gunnell, P. S., and Gubler, W. D. 1992. Taxonomy and morphology of Colletotrichum species pathogenic to strawberry. Mycologia 84:157-165.

16. Johnston, P. R., and Jones, D. 1997. Relationship among Colletotrichum isolates from fruitrots assessed using rDNA sequences. Mycologia 89:420-430.

17. Kuramae-Izioka, E. E., Lopes, C. R., Souza, N. L., and Machado, M. A. 1997. Morphological and molecular characterization of Colletotrichum spp. from citrus orchards affected by postbloom fruit drop in Brazil. Eur. J. Plant Pathol. 103:323-329.

18. Lardner, R., Johnston, P. R., Plummer, K. M. and Pearson, M. N. 1999. Morphological and molecular analysis of Colletotrichum acutatum sensu lato. Mycol. Res. 103:275-285.

19. Lathan, A. J., and Williams, J. C. 1983. Cultural characteristics and pathogenicity of Glomerella cingulata isolates from apples in Alabama. Plant Dis. 67:1065-1068.

20. Leite, R. P., Tsuneta, M., and Kishino, A. Y. 1988. Ocorréncia de mancha foliar de Glomerella em macieira no Estado do Paraná. Fundação Instituto Agronômico do Paraná. Informe da Pesquisa, 81 .

21. Puhalla, J. E. 1985. Classification of strains of Fusarium oxysporum on the basis of vegetative compatibility. Can. J. Bot. 63:179-183.

22. Shi, Y., Correll, J. C., and Guerber, J. C. 1996. Frequency of Colletotrichum species causing bitter rot of apples in the southeastern United States. Plant Dis. 80:692-696.

23. Struble, F. B., and Keitt, G. W. 1950. Variability and inheritance in Glomerella cingulata (Stonem.) S. and V. S. from apple. Am. J. Bot. 37:563-576.

24. Sutton, T. B. 1990. Bitter rot. Pages 15-16 in Compendium of Apple and Pear Diseases. A. L. Jones, and H. S. Aldwinckle, eds. American Phytopathological Society, St. Paul, MN.

25. Sutton, T. B., and Sanhueza, R. M. 1998. Necrotic leaf blotch of Golden DeliciousGlomerella leaf spot: A resolution of common names. Plant Dis. 82:267-268.

26. Talhinhas, P., Sreenivasaprasad, S., NevesMartins, J., and Oliveira, H. 2002. Genetic and morphological characterization of Colletotrichum acutatum causing anthracnose of lupins. Phytopathology 92:986-996.

27. Ureña-Padilla, A. R., MacKenzie, S. J., Bowen, B. W., and Legard, D. E. 2002. Etiology and population genetics of Colletotrichum spp. causing crown and fruit rot of strawberry. Phytopathology 92:1245-1252.

28. Yang, H. A., and Sweetingham, M. W. 1998 The taxonomy of Colletotrichum isolates associated with lupin anthracnose. Aust. J. Agric. Res. 49:1213-1223. 